\title{
Suggestions for "Safe" Residue Substitutions in Site-directed Mutagenesis
}

\author{
Domenico Bordo ${ }^{1,2}$ and Patrick Argos ${ }^{1}$ \\ ${ }^{1}$ European Molecular Biology Laboratory \\ Meyerhofstrasse 1, Postfach 102209 \\ 6900 Heidelberg, Federal Republic of Germany \\ ${ }^{2}$ Istituto Nazionale Ricerca sul Cancro \\ $V$. Benedetto $X V, 10$ \\ 16132 Genova, Italy
}

(Received 19 July 1990; accepted 22 October 1990)

\begin{abstract}
The conserved topological structure observed in various molecular families such as globins or cytochromes $c$ allows structural equivalencing of residues in every homologous structure and defines in a coherent way a global alignment in each sequence family. A search was performed for equivalent residue pairs in various topological families that were buried in protein cores or exposed at the protein surface and that had mutated but maintained similar unmutated environments. Amino acid residues with atoms in contact with the mutated residue pairs defined the environment. Matrices of preferred amino acid exchanges were then constructed and preferred or avoided amino acid substitutions deduced. Given the conserved atomic neighborhoods, such natural in vivo substitutions are subject to similar constraints as point mutations performed in site-directed mutagenesis experiments. The exchange matrices should provide guidelines for "safe" amino acid substitutions least likely to disturb the protein structure, either locally or in its overall folding pathway, and most likely to allow probing of the structural and functional significance of the substituted site.
\end{abstract}

\section{Introduction}

Site-directed mutagenesis has become a very important and yet facile tool to explore the structural and functional significance of particular residues within proteins (for example, see Knowles, 1987; Shaw, 1987; Gruetter et al., 1987). A typical experiment would involve substitutions of an amino acid thought to be essential for catalysis and then assaying the resultant variant for activity. It is central to the success of these experiments that disturbance of the protein fold and structural characteristics, locally as well as globally, be kept to a minimum; otherwise the loss of activity, for instance, would be a result of conformational changes and the exchanged residue be improperly identified as catalytic. Residue substitutions, where the latter situation does not occur, can be considered as "safe".

Natural evolution has "engineered" protein structures by modifying certain molecular properties such as substrate specificity or surface charges and yet conserved the global protein topology. By comparing known conserved three-dimensional protein structures it is possible to glcan hints about how this process was performed (Lesk \& Chothia,
1980, 1982; Chothia \& Lesk, 1986; Bashford et al. 1987); rules obtained in this way are useful for designing site-directed mutagenesis experiments. Protein engineering in the laboratory often faces similar trials. For example, suppose that charges on a protein surface are to be altered to construct a cation binding site. Which amino acids near the surface would be safer to substitute to achieve the desired charge configuration?

In this work residue exchange matrices are calculated that represent point mutational preferences as observed in homologous and known threedimensional protein structures. Alignments of primary sequences determined from spatial superposition of the main-chain $\mathrm{C}^{\alpha}$ and taken from nine molecular families allowed identification of structurally equivalent residues in each of the familial sequence sets. A search was then performed for equivalent residues that had mutated but maintained similar unmutated environments defined by these atoms in contact with the central residue pairs. Such point mutations as observed in known tertiary structures are likely to be, with present-day knowledge, the closest possible mimic of in vivo sitedirected mutagenesis.

Residue exchange statistics and their significance 
were determined for all the structural equivalents in the various molecular families. The preferred and avoided substitutions were elicited from three structural contexts: buried residues, amino acids exposed beyond some water-accessible surface area threshold, and then all cases regardless of accessible state. These exchange matrices should provide considerable aid in the difficult process of deciding which residue to exchange and then with which amino acid it should be substituted to maintain protein structural integrity. The preferred exchanges are also discussed in terms of residue physicochemical characteristies.

\section{Data and Methods}

\section{(a) Aligned structures}

Aligned sequence sets were taken from 9 molecular families: globins, immunoglobulins, eytochromes $c$, serine proteases, subtilisins, calcium binding proteins, acid proteases, toxins, and virus capsid proteins. The total number of sequences, each with known 3-dimensional structure as contained in the 1989 Brookhaven database collection (Bernstein et al., 1977), was 55. Table 1 lists their database code identification, protein name, species, reference for the 3-dimensional structure, and, where present, reference in which the alignment of the familial sequences used here was determined. The alignments were generally achieved by careful examination of the X-ray crystallographic structures coupled with spatial superposition of the main-chain $\mathrm{C}^{\alpha}$ atoms (Rossmann \& Argos, 1981). In 3 cases (calcium binding proteins, acid proteases and toxins) structures were superimposed by the present authors using the technique of Rossmann \& Argos (Rossmann \& Argos, 1976, 1977; Argos \& Rossmann, 1979). Due to the increasing number of solved protein structures, many of those used in the present work extracted from the 1989 release of the Brookhaven database were not included in the references showing the familial alignments. These further sequences, indicated by an asterisk in Table 1, were aligned by the authors to the closest family member in both sequence and structure.

When considering statistics for buried residues (solventaccessible surface area below an upper limit), both constant and variable domains were utilized from the immunoglobulins. However, the variable regions were excluded from the exchange matrix statistics involving surface-exposed amino acids, since large segments of the variable domain loops bind antigens and therefore are subject to special constraints. For a similar reason, sidechains contributing to subunit interface or cofactor contacts were not included in the substitution calculations.

\section{(b) Similarity of environment}

In a previous paper, Bordo \& Argos (1990) carefully defined a measure of similarity (see $S^{\prime \prime}$ as given by them in eqns (1) and (3)) between 2 atomic environments surrounding structurally equivalent residues. The same measure is used here. An environment or neighborhood for a residue (called a central residue) is defined by the number of atoms and amino acid types that are within $4.5 \AA(1 \AA=0.1 \mathrm{~nm})$ of any side-chain atom in the surrounded residue. The similarity score $S$ is expressed as a fraction and is defined as:

$$
S=\frac{\sum_{i}\left(\overline{b_{i}}+\overline{s_{i}} \delta_{i}\right)}{\sum_{i}\left(\overline{b_{i}}+\overline{s_{i}}\right)}
$$

The denominator is simply the mean number of atoms belonging to residues present in at least 1 of the 2 environments $\left(\vec{b}_{i}=\right.$ main-chain atoms, $\bar{s}_{i}=$ side-chain atoms). The mean refers to the 2 sets of atoms in each of the 2 environments. The numerator is the sum of the mean number of all main-chain atoms by the 2 environments regardless of the mutational state of the equivalent neighborhood residues plus the mean number of side-chain atoms $\overline{s_{i}}$ from residucs that touch at least 1 atom of the mutated central residues (i.e. within $45 \AA$ ). The term $\delta_{i}$ is 0 if the $i$ th residue is mutated and 1 if identically conserved. $\sum_{i}$ is over all residues that touch at least 1 of the central residues. Therefore, similarity of 2 environments will be diminished only if there are mutations in the equivalent environmental residues. That is, if structurally equivalent residues forming the neighborhood of a central residue in 1 protein structure are conserved in the other structure despite their absence in the neighborhood of the equivalent central residue in the latter structure, the similarity score is not decreased. This allows for cases where contacts made by the substituted central residue with its neighbors change only in consequence of its change in size and shape. For instance, environmental residues can move considerably to accommodate a small residue changing to a large one. 'Though the side-chains in contact with the larger residue are not in contact with the small one, they are nonetheless available without mutation to make contact as necessitated by the substituted residue. Water-accessible surfaces of the combined main-chain and side-chain for each residue was calculated by the procedure of Kabsch \& Sander (1983).

\section{(c) Statistical significance of exchanges}

Counts were made for every observable substitution of central residues with similar neighborhood at a preset similarity threshold. To give statistical significance to these figures, a comparison between observed and expected number of substitutions was performed under the following hypothesis. Consider a pool of $N$ amino acids. $N=\sum_{i} n_{i}(i=1$ to 20$)$, where the $i$ th amino acid type appears $n_{i}$ times. The exchange $i \rightarrow j$ is a directed replacement of the amino acid $i$ with the amino acid $j$ (e.g. Ala $\rightarrow$ Asp) and substitution $i-j$ refers to either $i \rightarrow j$ or $j \rightarrow i$ (e.g. Ala $\rightarrow$ Asp or $\Lambda$ sp $\rightarrow \Lambda$ la). There are $N(N-1)$ possible exchanges in the pool, of which $\sum_{i} n_{i}\left(n_{i}-1\right)$ are between residues of the same kind. Therefore, $N^{\prime}=N(N-1)-\sum_{i} n_{i}\left(n_{i}-1\right)$ is the number of possible exchanges involving pairs of different residues. Since the observed mutations refer to only substituted residnes, $N^{\prime}$, and not $N$, represents the pool of available exchanges. The probability $p_{i \rightarrow j}$ is then given by $n_{i} n_{j} / N^{\prime}$, and the probability to observe a substicution $p_{i-j}$ becomes:

$$
p_{i-j}=2 n_{i} n_{j} / N^{\prime}
$$

Given a total number of $X$ observed substitutions, the expected number of substitutions $n_{i-j}$ is therefore $X p_{i-j}$.

The population $n_{i}(i=1$ to 20 ) was calculated in the following manner. Given a set of structurally aligned sequences for a particular molecular family, each alignment column would generally contain several amino acid types. The count for the population $n_{i}(i=1$ to 20$)$ was 
Table 1

Tertiary structures used in this work

\begin{tabular}{|c|c|c|c|c|c|}
\hline Family & $\mathrm{BRK} \dagger$ & Protein & Origin & Structure reference & Alignment reference $\ddagger$ \\
\hline \multirow[t]{9}{*}{ Hemoglobin } & & & & & Lesk \& Chothia (1980) \\
\hline & $4 \mathbf{H H B}$ & Hemoglobin & Human & Fermi et al. (1984) & \\
\hline & $2 \mathrm{MHB}$ & Hemoglobin & Equine & Ladner et al. (1977) & \\
\hline & IFDH & Gamma globin & Human & Frier \& Perutz (1977) & * \\
\hline & IMBD & Myoglobin & Whale & Phillips (1980) & \\
\hline & IMBS & Myoglobin & Seal & Scouloudi \& Backer (1978) & * \\
\hline & 2LHB & Hemoglobin V & Sea lamprey & Hendrickson et al. (1973) & \\
\hline & $1 \mathrm{ECA}$ & Erythrocruorin & Chironomous & Steigemann \& Weber (1979) & \\
\hline & $2 \mathrm{LH} 1$ & Leghemoglobin & Lupin & Vainshtein et al. (1977) & \\
\hline \multirow[t]{13}{*}{ Immunoglobulins } & & & & & Amzel \& Poljak (1979) \\
\hline & $1 F B 4$ & FAB Kol & Human & Marquart et al. (1980) & $*$ \\
\hline & IFBJ & FAB IgA & Mouse & Navia et al. (1979) & * \\
\hline & $\mathrm{IFCl}$ & FcIggl & Fuman & Deisenhofer (1981) & * \\
\hline & $1 \mathrm{FC} 2$ & $\mathrm{Fe}$ & Human & Deisenhofer (1981) & * \\
\hline & IIG2 & Fc Kol & Human & Marquart et al. (1980) & * \\
\hline & IMCP & FAB & Mouse & Segal et al. (1974) & $*$ \\
\hline & IPFC & Fe Iggl & Porcine & Bryant et al. (1985) & $*$ \\
\hline & IREI & FAB Bence-Jones & Human & Epp et al. (1975) & * \\
\hline & $2 \mathrm{RHE}$ & FAB Bence-Jones & Human & Furey et al. (1983) & $*$ \\
\hline & $3 \mathrm{FAB}$ & FAB New & Human & Saul et al. (1978) & \\
\hline & 2HFL & FAB Iggl & Mouse & Sheriff et al. (1987) & $*$ \\
\hline & $1 F 19$ & $\mathrm{FAB}$ & Mouse & Lascombe et al. (1989) & * \\
\hline \multirow[t]{7}{*}{ Cytochromes $c$} & & & & & Dickerson (1980) \\
\hline & $155 \mathrm{C}$ & Cytochrome $c 550$ & Paracoccus D & Timkovich \& Dickerson (1976) & \\
\hline & $3 \mathrm{C} 2 \mathrm{C}$ & Cytochrome $c 2$ & Rhodospirillum $\mathbf{R}$ & Salemme et al. (1973) & \\
\hline & 4CYT & Cytochrome $c$ & Bonito fish & Takano \& Dickerson (1980) & \\
\hline & $1 \mathrm{CYC}$ & Ferrocytochrome $c$ & Tuna fish & Tanaka et al. (1975) & * \\
\hline & 1CCR & Cytochrome $c$ & Rice & Ochi et al. (1983) & * \\
\hline & $451 \mathrm{C}$ & Cytochrome $c 551$ & Pseudomonas A & Matsuura et al. (1982) & \\
\hline \multirow[t]{12}{*}{ Serine proteases } & & & & & Craik et al. (1983) \\
\hline & $2 \mathrm{SGA}$ & Proteinase A & Streptomyces $\mathrm{G}$ & Moult et al. (1985) & \\
\hline & $3 \mathrm{SGB}$ & Proteinase B & Streptomyces $\mathrm{G}$ & Kead et al. (1983) & \\
\hline & 2ALP & Alpha-lytic protease & Lysobacter E. & Fujinaga et al. (1985) & \\
\hline & $4 \mathrm{CHA}$ & Alpha chymotrypsin & Bovine & Tsukada \& Blow (1985) & \\
\hline & 3РTB & Beta trypsin & Bovine & Marquart et al. (1983) & \\
\hline & 2TRM & Trypsin & Rat & Sprang et al. (1987) & $*$ \\
\hline & ITON & Tonin & Rat & Fujinaga \& James (1987) & * \\
\hline & $2 \mathrm{KAI}$ & Kallikrein & Porcine & Bode et al. (1983) & * \\
\hline & $1 \mathrm{SGT}$ & Trypsin & Streptomyces $\mathrm{G}$ & Read \& James (1988) & * \\
\hline & 3EST & Elastase & Poreine & Meyer et al. (1988) & * \\
\hline & $3 \mathrm{RP2}$ & Mast cell protease & Rat & Remington et al. (1988) & $*$ \\
\hline \multirow[t]{4}{*}{ Subtilisins } & & & & & Froemmel \& Sander \\
\hline & 1SBT & Subtilisin & $\begin{array}{l}\text { B. amylolique- } \\
\text { facensis }\end{array}$ & Alden et al. (1971) & $(1989)$ \\
\hline & $2 \mathrm{PRK}$ & Proteinase K & Fungus & Paehler et al. (1984) & \\
\hline & $1 \mathrm{CSE}$ & Subtilisin Karlsberg & B. subtilis & Bode $e t$ al. (1987) & \\
\hline \multicolumn{6}{|c|}{ Calcium binding proteins } \\
\hline & 3CLN & Calmodulin & Rat & Babu et al. (1988) & $*$ \\
\hline & $3 \mathrm{CPV}$ & $\begin{array}{l}\text { Ca-binding } \\
\text { parvalbumin B }\end{array}$ & Carp & Moows \& Kretsinger (1975) & $*$ \\
\hline & $3 \mathrm{ICB}$ & Ca binding protein & Bovine & Szebenyi \& Moffat (1986) & $*$ \\
\hline & $4 \mathrm{TNC}$ & Troponin $\mathrm{C}$ & Chicken & Satyshur et al. (1988) & $*$ \\
\hline \multicolumn{6}{|l|}{ Acid proteases } \\
\hline & $\begin{array}{l}2 A P P \\
2 A P R\end{array}$ & & Fungus & $\begin{array}{l}\text { James \& Sielecki (1983) } \\
\text { Suguna et al. (1987) }\end{array}$ & * \\
\hline & $4 \mathrm{APE}$ & Endothiapepsin & $\begin{array}{l}\text { Miold } \\
\text { Fungus }\end{array}$ & Pearl \& Blundell (1984) & * \\
\hline \multicolumn{6}{|c|}{ ( } \\
\hline & ICTX & Alpha cobratoxin & Cobra & Walkinshaw et al. (1980) & $*$ \\
\hline & $1 \mathrm{NXB}$ & Neurotoxin B & Sea snake & Tsernoglou et al. (1978) & * \\
\hline & $2 \mathrm{ABX}$ & Alpha bugarotoxin & Krait & Love \& Stroud (1986) & * \\
\hline Viruses & & & Virus & & Rossmann et $a i$. (1983) \\
\hline & $4 \mathrm{SBV}$ & Southern bean mosaic & Virus & Silva \& Rossmann (1985) & Toussinatint et cat. (1900) \\
\hline & $2 \mathrm{STV}$ & Satellite tobacco necr. & Virus & Jones \& Liljas (1984) & \\
\hline & IMEV & Mengo & Virus & Luo et al. (1987) & Luo et al. (1987) \\
\hline & $4 \mathrm{RHV}$ & Rhino & Virus & Arnold \& Rossmann (1988) & Luo et al. (1987) \\
\hline
\end{tabular}

† The column labeled BRK gives the Brookhaven database entry name (Bernstein et al., 1977).

\$ References showing structural sequence alignments used in this work. An asterisk refers to the cases where the structural alignment was performed by the authors. 
Table 2

Residue counts for the nine structural protein families

\begin{tabular}{lrrr}
\hline Residue type & Buried $\dagger$ & Exposed & All \\
\hline Gly & 161 & 226 & 445 \\
Ala & 182 & 250 & 515 \\
Ser & 108 & 375 & 533 \\
Pro & 34 & 194 & 249 \\
Asp & 28 & 255 & 315 \\
Cys & 38 & 23 & 71 \\
Asn & 33 & 258 & 313 \\
Thr & 79 & 341 & 477 \\
Glu & 11 & 239 & 255 \\
Val & 206 & 166 & 415 \\
Gln & 26 & 201 & 248 \\
His & 20 & 69 & 105 \\
Met & 49 & 47 & 107 \\
Leu & 165 & 135 & 331 \\
Ile & 125 & 104 & 265 \\
Lys & 5 & 297 & 320 \\
Arg & 9 & 162 & 193 \\
Phe & 89 & 88 & 208 \\
Tyr & 38 & 128 & 191 \\
Trp & 30 & 33 & 68 \\
\hline
\end{tabular}

$\dagger$ Residues having solvent-accessible surface less than or equal to $10 \AA^{2}$. Counts are performed as described in Data and Methods.

\$ Residues having solvent-accessible surface more than or equal to $30 \AA^{2}$. Counts are performed as deseribed in Data and Methods.

$\S$ All residues are counted, regardless of their exposure to solvent.

increased by 1 only once for each amino acid type in the alignment column, regardless of its number of appearances. This was consistent with the counts for redundant central residue pairs. For instance, suppose an alignment position contained 3 Ala and 2 Gly residues in a particular topologic family, a total of 6 residue substitutions can be counted; however, since they are all structurally equivalent, only 1 should be taken; namely, that Gly-Ala substitution with the highest environmental similarity score. This selection is consistent with the aim of this study to find conserved neighborhoods tolerating mutant central residues. Total counts $n_{i}(i=1$ to 20 ) were determined for all the alignment positions in all the molecular families under 3 water-accessible conditions and are given in Table 2 . The probability to observe $\alpha$ substitutions $i-j$ out of $X$ trials taken from a pool of $N$ residues $\left(N=\sum_{i} n_{i}\right)$ assuming a binomial distribution is given by:

$$
P_{i-j}(X, \alpha)=\left(\begin{array}{c}
X \\
\alpha
\end{array}\right) p_{i-j}^{\alpha}\left(1-p_{i-j}\right)^{\mathrm{X}-\alpha}
$$

where $p_{i-f}$ is given in eqn (2), and:

$$
\left(\begin{array}{l}
X \\
\alpha
\end{array}\right)=\frac{X !}{\alpha !(X-\alpha) !}
$$

Given the number of observed substitutions $n_{i-j}$, it is straightforward to calculate its chance probability with eqn (3) (see e.g. Korn \& Korn, 1968). If the sum of all probabilities $p_{i-j}(X, \alpha)$ for $n_{i-j} \leq \alpha \leqslant X$ is less than or equal to 0.05 , the preference of the substitutions can be considered significant at the $95 \%$ confidence level or better. Consider the following hypothetical illustration. Suppose the pool of residues consisted of 10 amino acids for each of
Table 3

Number of substitutions for buried residues involving volume and polarity alterations

\begin{tabular}{lcrrrrr}
\hline Similarity (\%)† & 100 & 95 & 90 & 85 & 80 \\
\hline $\begin{array}{l}\text { Observed substitutions } \\
\begin{array}{c}\text { Total number with volume } \\
\text { change > 1 methyl group }\end{array}\end{array}$ & 12 & 34 & 65 & 124 & 206 \\
$\begin{array}{c}\text { Total number with polarity } \\
\text { group change }\end{array}$ & 2 & 2 & 14 & 33 & 63 \\
$\begin{array}{l}\text { Hydrophobic/hydrophilic } \\
\text { substitutions }\end{array}$ & - & - & 1 & 1 & 1 \\
\hline $\begin{array}{l}+ \text { Percentage similarity } \\
\text { environments (see eqn (1)). }\end{array}$ & threshold of central & residue
\end{tabular}

the 20 types $\left(n_{i}=10, i=1\right.$ to 20$)$, then $N=200$ and the number of possible non-identical amino acid exchanges $N^{\prime}$ is:

$$
(200 \times 199)-\sum_{i}(10 \times 9)=38,000 .
$$

If, for instance, 1000 substitutions are observed $(X=$ $1000)$, the expected $n_{i-j}$ using eqn (2), is $2 \times 1000 \times 10$ $\times 10 / 38,000 \sim 6$. Assume that for a given pair $\dot{i}-j$ (e.g. Ala--Thr) the observed number of substitutions $n_{\mathrm{Ala}-\mathrm{Thr}}$ is 12 , then if

$$
\begin{array}{r}
P_{\text {Ala-Thr }}(1000,12)+P_{\text {Ala-Thr }}(1000,13)+\ldots+ \\
P_{\text {Ala-Thr }}(1000,1000)<=0.05
\end{array}
$$

the substitution preference between Ala and Thr can be considered significant with at least $95 \%$ confidence.

\section{Results and Discussion}

Table 2 lists the residue population for each of the amino acids in the three structural states examined for central residue substitutions: (1) buried in the protein core (solvent-accessible surface for both residues $\leq 10 \AA^{2}$ ); (2) exposed (solvent-accessible surface area $\geq 30 \Lambda^{2}$ ); and (3) all the possible access ibility states allowed. The residue pool represents, under the constraints discussed in Data and Methods, the composition of amino acids available for possible substitutions. These populations are important in calculating the substitution statistical significance (see Data and Methods).

In a previous paper (Bordo \& Argos, 1990), substitution statistics were gathered from only one sequence family (globins) and for only buried residues. The buried exchange counts given here increased by at least a factor of 5 from the addition of eight sequence families (Table 1). The basic trends observed were nonetheless conserved. The results in Table 3 make this salient. Very few of the total substitutions show volume changes greater than one methyl group $\left(\sim 35 \AA^{3}\right)$ and a movement (referred to as a "jump") to another polarity group (Grantham, 1974) where the three possible groups are defined (1 letter code used) by (WYFMCILV), (PATGS) and (HKRQDEN). These constraints imply considerable impact on the development of protein cores in structures maintaining main-chain fold; a detailed discussion can be found in the earlier work (Bordo \& Argos, 1990), All ensuing work given here is unique to this report. 
Table 4

Number of substitutions for exposed residues involving volume and polarity alterations

\begin{tabular}{lrrrrr}
\hline Similarity (\%) & 100 & 95 & 90 & 85 & 80 \\
\hline $\begin{array}{l}\text { Observed substitutions } \\
\text { 'lotal number with volume } \\
\text { change > 1 methyl group }\end{array}$ & 100 & 152 & 322 & 560 & 941 \\
$\begin{array}{c}\text { Total number with polarity } \\
\text { group change }\end{array}$ & 42 & 69 & 153 & 280 & 547 \\
$\begin{array}{l}\text { Hydrophobic/hydrophilic } \\
\text { substitutions }\end{array}$ & 3 & 5 & 19 & 39 & 78 \\
\hline $\begin{array}{l}+ \text { Percentage similarity } \\
\text { environments (see eqn (1)). }\end{array}$ & threshold of & central & residue
\end{tabular}

Table 4 lists similar statistics (volume and polarity group alteration counts) for exposed residues with similar environments. It is clear that they display considerable point mutation freedom compared to the buried residues. Approximately one-third to one-half of the substitutions (depending on the percentage similarity of the neighborhood) involve changes in polarity group or volume alterations greater than one methyl group, whereas only about $15 \%$ of the buried substitutions involved such changes. However, few side-chains $(\sim 5 \%)$ alter the sign of their charge or jump $(\sim 3 \%)$ between opposite polarity groups (i.e. hydrophobichydrophilic) despite their exposure.

It was insisted that each of the two substituted residues have a water-accessible surface area of at least $30 \AA^{2}$ to be deemed exposed. This represents approximately a hole just large enough for a methyl group to pass through and was found from the previous globin statistics (Bordo \& Argos, 1990) as well as the present data (not shown) to be the minimal exposure at which radical volume and polar alterations between exchanged central residues are observed.

Figure 1 shows the actual exchange counts for (a) buried, (b) exposed and (c) all cases where the central residue environments were $90 \%$ or greater (lower matrix half) and $70 \%$ or greater (upper matrix half) in similarity. The symbols plus (preferred exchange) and minus (avoided exchange) are shown in the upper half of matrices if the counts were reliable at the $95 \%$ confidence level or better as well as consistently preferred or shunned for at least two similarity levels within a range of $100 \%$ to $70 \%$ calculated in steps of $5 \%$. As expected, the $70 \%$ similarity data produced the most observed exchange counts and the greatest number of substitutions deemed significant. However, given the lessened neighborhood similarity, noise is increasingly introduced; nonetheless, trends are preserved from the $90 \%$ to $70 \%$ levels (Fig. 1).

Several interesting substitution trends are observable in the Figure 1 exchange matrices. Though the high count substitutions are not always deemed statistically significant, they represent a useful starting point in deciding which substitutions to try in structure-altering experiments as site-directed mutagenesis or protein engineering. It will take considerable time and effort to produce sufficient $\mathrm{X}$-ray crystallographic protein structures to determine the significance of all the possible substitutions.

For the protein core, residues within each of the following subsets are generally interchangeable with high statistical significance: $(A, G),(A, V),(N, D)$, $(\mathrm{M}, \mathrm{L}),(\mathrm{F}, \mathrm{L}),(\mathrm{F}, \mathrm{Y}),(\mathrm{A}, \mathrm{S}, \mathrm{T}),(\mathrm{V}, \mathrm{I}, \mathrm{L})$ and $(\mathrm{Y}, \mathrm{W})$. This is shown diagrammatically in Figure 2. In an examination of the counts alone, surprising results can be found for many of the amino acid types. While Thr can exchange with Ala and Ser, Asn is the next most desirable. Cys prefers Ala or Val as substitutes. Though Val can rather freely go to Ala, Ile and Leu, Ile prefers primarily only Val and Leu. Met and Phe favor Leu, rather than lle, as an ersatz. For exposed substitutions unexpected results arc also in evidence. Gly prefers Asn as the most desirable charged or polar substitute. If Ala must be replaced by a charged residue, Lys and Glu are statistically favored. Ser prefers Asp and Asn and not Glu, Lys or Arg, while Thr is the most favored substitute. Asp especially avoids Tyr at the surface. Val's favorite partners are Ile and Leu, while Tyr prefers Phe. Interestingly, the hydrophobic residues Val, Leu and Ile tend to substitute amongst themselves despite some exposure at the surface. If an exposed Val must be changed to a charged residue, Lys is the best candidate; and so forth.

Some substitutions are consistently allowed regardless of exposure or buriedness (Fig. 2). Among the highly significant preferred exchanges, in single letter code, are $(\mathrm{G}, \mathrm{A}),(\mathrm{S}, \mathrm{A}),(\mathrm{T}, \mathrm{A}),(\mathrm{N}, \mathrm{D}),(\mathrm{T}, \mathrm{S})$, $(\mathrm{V}, \mathrm{I}, \mathrm{L})$ and $(\mathrm{F}, \mathrm{Y})$.

Calculating the logarithm of the ratio of the observed to expected counts for each possible substitution and for all observed cases having $70 \%$ environmental similarity (Fig. 1(c), upper right matrix), it was possible to build a scoring matrix analogous to that determined by Dayhoff et al. (1978). The correlation coefficient between the elements of the two matrices was $0 \cdot 64$. It would not be expected that the two matrices correlate well as the results of this work concern single substitutions over only close molecular generations, while the Dayhoff et al. observations are cumulative over many and multiple mutations.

The matrices listing preferred or safe and avoided or unsafe substitutions taken from actual tertiary structures should prove exceedingly useful in sitedirected mutagenesis and protein engineering experiments. It would be helpful to ascertain if a residue is exposed or buried before choosing a substitution. If the protein three-dimensional structure is known, this information is evident. If only the sequence has been determined, secondary structure prediction and/or a hydrophobicity plot (for a review, see Argos, 1990) should provide a good guess as to the appropriate solvent-accessible state of the residue in question. If not, the exchange counts taken from all residues in the familial sequence sets are given in Figure 1(c). 


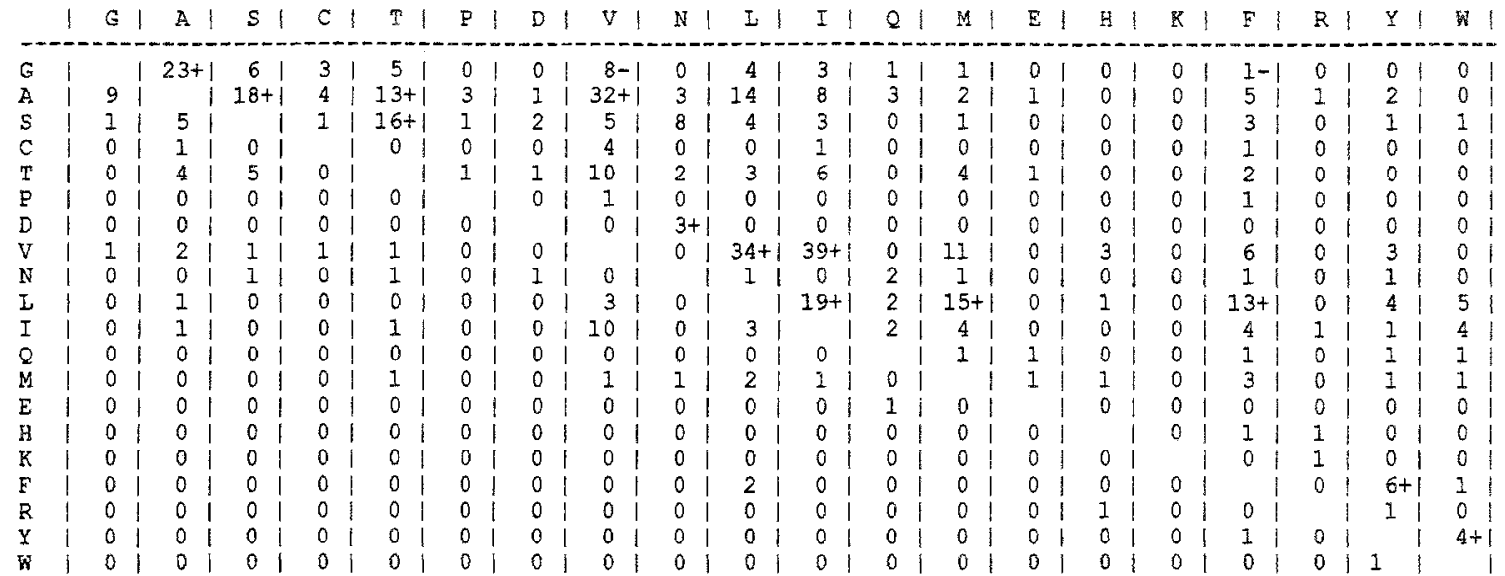

(a)

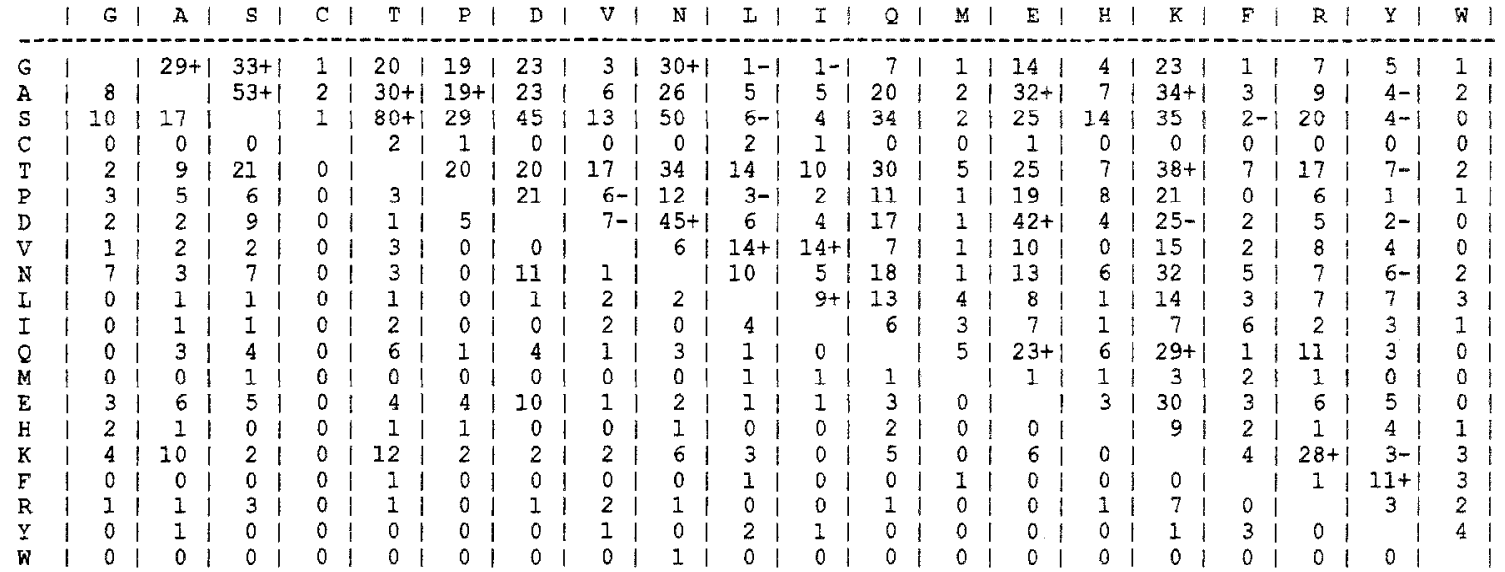

(b)

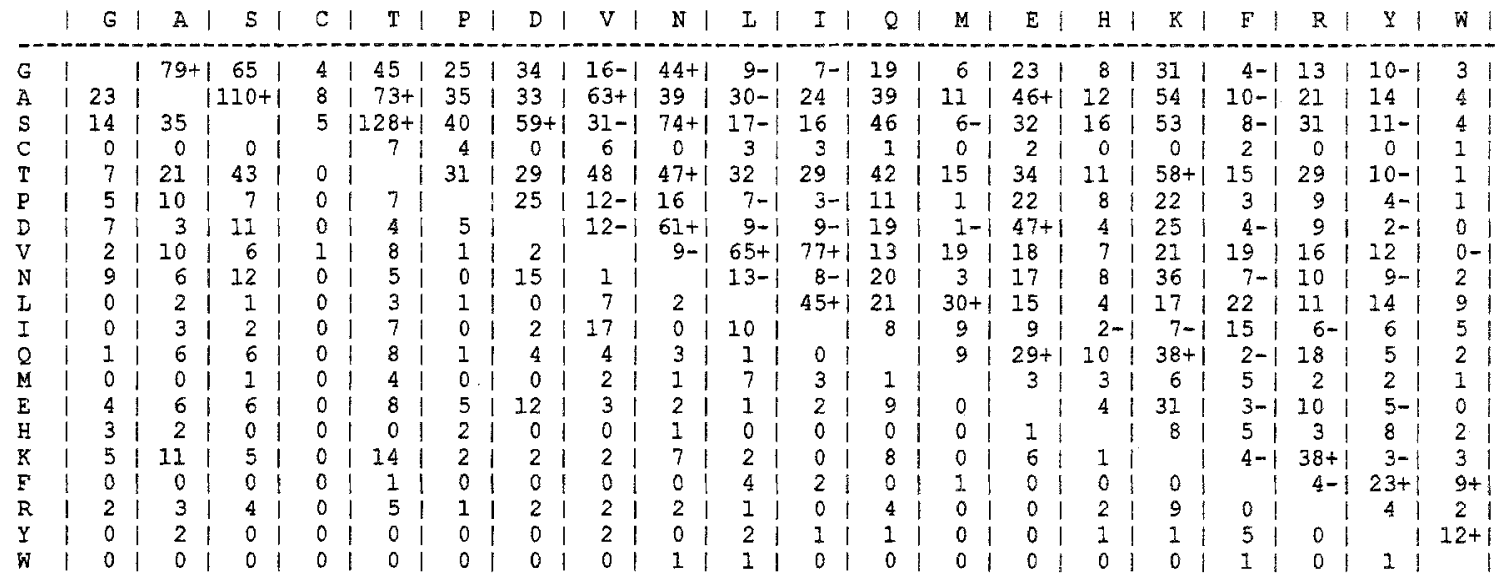

(c)

Figure 1. Observed substitutions for (a) buried, (b) exposed and (c) all cases. The lower halves of the matrices give substitution counts for central residues with $90 \%$ or greater similar environments, while the upper halves are for $70 \%$ or greater similarity. When counts show a statistically meaningful (95\% or greater confidence) increase or decrease compared to the expected figures for at least 2 similarity levels ranging from $100 \%$ to $70 \%$ in steps of $5 \%$, with the trend being consistent, a + or - sign is given to indicate preferred or avoided substitutions, respectively. In the exposed data, immunoglobulin variable domains were not included. 


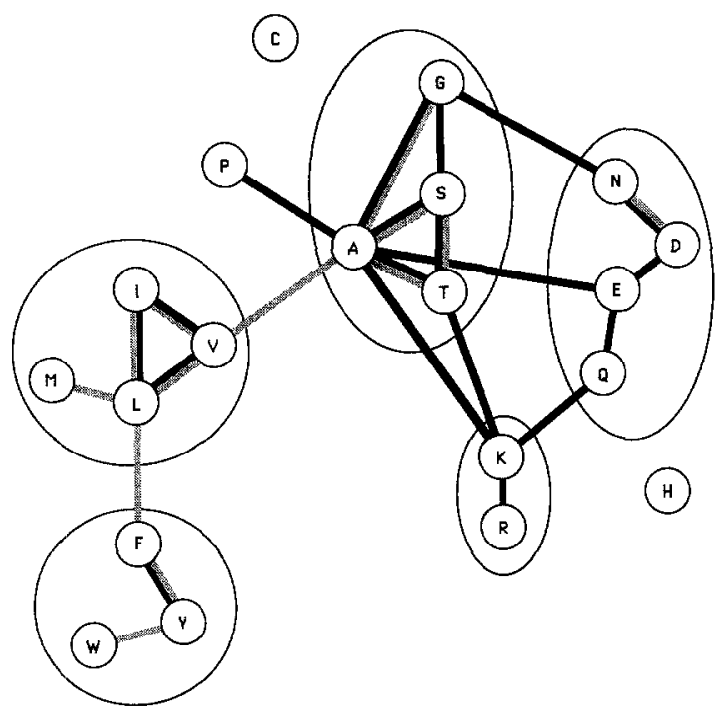

Figure 2. Statistically preferred (95\% or greater confidence level as indicated by a + in Fig. 1) substitutions observed in buried residues (grey segments) and exposed residues (black segments) are shown. Residues roughly equivalent are grouped together in 5 subsets, which gencrally correlate with side-chain physicochemical properties.

Lim \& Sauer (1989) have performed mutation experiments on $\lambda$ repressor protein core side-chains and the mutants were assayed for functionality and stability. Interestingly, all of the single protein core mutants could have been predicted from this work (Bordo \& Argos, 1990).

Site-directed mutagenesis is an important tool in probing the structural and functional significance of particular residues within a protein sequence (for reviews, see Knowles, 1987; Shaw, 1987). Amino acid residues might be altered to check for their participation in catalysis, cofactor or substrate binding, molecular and receptor recognition, domain interfaces, oligomeric interactions, and the like. It is essential in such experiments that the protein fold, locally and globally, not be perturbed; otherwise, loss of activity or whatever aspect is under study would be incorrectly ascribed to the mutated residue. "Safe" substitutions are thus requisite for the success of the mutant probe as an indicator of critical residues in structure and function. This work provides exchange matrices that should be directly applicable in maintaining the fold and that are taken from known three-dimensional protein structures with diverse folds. Of course, the results represent general trends and cannot be expected to work in every local context, but they should be a great improvement over randomly selected substitutions and act as a good guide regarding what to substitute and what not to substitute. For example, suppose Cys were a suspected active site residue. If exposed or buried, though the substitution data base is not sufficient to identify statistically significant exchanges for Cys, the observed substitutions counts would recommend Ala; if the Cys is likely to be buried, Val is also a possible candidate.
Zvelebil \& Sternberg (1988) examined several known tertiary structures and determined that His is the most frequently occurring catalytic residue. Assuming its exposure to the solvent, the exchange matrix suggests Ser as the safest substitution. In the review by Shaw (1987) on specific point mutations for several molecular species, the GlyAla substitution is one of the most frequent mentioned. Apparently the proteins maintained their fold while proven assays displayed altered activity. The exchange matrices presented in this work suggest the Gly-Ala substitution as highly significant in the buried or exposed states.

In protein engineering as well as molecular modeling, where new structures are built from those with known tertiary and homologous primary structures (for a review, see Sali et al., 1990), it is often crucial to know which residues can be substituted safely. Can a substituted residue in a molecular model be placed in the same environment displayed by the known native structure? For instance, if a His is to be introduced in an exposed loop to engineer cation binding, would it be safer to substitute a Ser, Glu, Asn or Lys in the known structure? The exchange matrices of Figure 1 provide direct answers. In faet, Sali et al. (1990) in their review on modeling cite only two specific examples where residues are allowed limited choices due to folding requirements. Both involve constrained Ser-Thr substitutions in buried $\beta$-strands where the sidechain oxygen aloms bond to main-chain atoms. Among the preferred exchanges, the Ser-Thr one is highly preferred both in the exposed and buried substitutions matrices reported here (Fig. 2). A further protein engineering example would involve a desired residue substitution to stabilize a predicted or known helix. The exchange should be from a residue of lower to higher helical preference (Palau et al., 1982). Combining this requirement with the exchange matrix counts of Figure 1 should provide a very rational substitution, especially if the tertiary structure is not known, which is typically the situation. For example, if Ile were buried and part of a helix is to be stabilized, the matrix of Figure 1(a) suggests Leu and then Met as likely substitution candidates.

Malcolm et al. (1990) have published results of mutants of game bird lysozymes. Point mutations on in vivo triplets Thr40-Ile55-Ser91 (TIS) or Ser40 Val55-Thr91 (SVT) included, respectively, TVS, SIS, TIT and SVS, SIT, TVT. The mutants were assayed for thermal stability and it was found that TIT, SIT and TVT were more stable than the respective wild-type and TVS, SIS and SVS less so. The buried-residue exchange matrices in this work would predict that $\mathrm{Val} \rightarrow \mathrm{Ile}$ and $\mathrm{Ser} \rightarrow \mathrm{Th}$ would be ideal substitutions to preserve main-chain fold and enhance thermal stability under the assumption that increasing the volume of a side-chain within one methyl group would result in better hydrophobic packing to maintain the protein structure. In every case, this is exactly what occurred experimentally. In fact, when the exchange from the wild- 
type involved a volume decrease, the fold was maintained but thermal stability diminished.

The authors thank Gareth Chelvanayagam, Jaap Heringa and Peter Sibbald for many helpful discussions.

\section{References}

Alden, R. A., Birktoft, J. J., Kraut, J., Robertus, J. D. \& Wright, C. S. (1971). Biochem. Biophys. Res. Commun. 45, 337-449.

Anzel, L. M. \& Poljak, R. (1979). Annu. Rev. Biochem. 48, 961-997.

Argos, P. (1990). Methods Enzymol. 182, 751-776.

Argos, P. \& Rossmann, M. G. (1979). Biochemistry, 18 4951-4960.

Arnold, E. \& Rossmann, M. G. (1988), Acta Crystallogr sect. $A, 44,270-282$.

Babu, Y. S., Bugg, C. E. \& Cook, W. J. (1988). J. Mol. Biol. 204, 191-204.

Bashford, D., Chothia, C. \& Lesk, A. M. (1987). J. Mol Biol. 196, 199-216.

Bernstein, F. C., Koetzle, T. F., Williams, G. J. B., Meyer E. F., Brice, M. D., Rodgers, J. R., Kennard, O. Schimanouchi, T. \& Tasumi, M. (1977). J. Mol. Biol. $112,535-542$

Bode, W., Chen, Z., Bartels, K., Kutzbach, C., SchmidtKastner, G. \& Bartunik, H. (1983). J. Mol. Biol. 164 237-282.

Bode, W., Papamokos, E., \& Musil, D. (1987). Eur. J Biochem. 166, 673-692.

Bordo, D. \& Argos, P. (1990). J. Mol. Biol. 211, 975-988.

Bryant, S. H., Amzel, L. M., Phizackerley, R. P. \& Poljak, R. J. (1985). Acta Crystallogr. sect. B, 41 $362-368$.

Chothia, C. \& Lesk, A. M. (1986). EMBO J. 5, 823-826.

Craik, C. S., Rutter, W. R. \& Fletterick, R. (1983) Science, 220, 11251129

Dayhoff, M. O., Schwartz, R. M. \& Orcutt, B. C. (1978). Atlas of Protein Sequence and Structure, vol. 5, suppl.3, pp. 345-362. National Biochemical Foundation, Georgetown University Medical Center, Washington, DC.

Deisenhofer, J. (1981). Biochemistry, 20, 2361-2370.

Dickerson, R. E. (1980). Sci. Amer. 242, 98-112.

Epp, O., Lattman, E. E., Suhiffer, M., Huber, R. \& Pulm W. (1975). Biochemistry, 14, 4943-4952.

Fermi, G., Perutz, M. F., Shaanan, B. \& Fourme, R (1984). J. Mol. Biol. 175, 159-174.

Frier, J. A. \& Perutz, M. F. (1977). J. Mol. Biol. 112 97-112.

Froemmel, C. \& Sander, C. (1989). Proteins, 5, 22-37.

Fujinaga, M. \& James, M. N. G. (1987). J. Mol. Biol. 195 373-396.

Fujinaga, M., Delbaere, L. T. J., Brayer, G. D. \& James, M. N. G. (1985). J. Mol. Biol. 84, 479-502

Furey, W., Jr, Wang, B. C., Yoo, C. S. \& Sax, M. (1983). J. Mol. Biol. 167, 661-692.

Grantham, R. (1974). Science, 185, 862-864.

Gruetter, M. G., Gray, T. M., Weawer, L. H., Alber, T. Wilson, K. \& Matthews, B. W. (1987). J. Mol. Biol. 197, $315-329$

Hendrickson, W. A., Love, W. E. \& Karle, J. (1973) J. Mol. Biol. 74, 331-361.

Hopper, P., Harrison, S. C. \& Sauer, R. T. (1984). J. Mol. Biol. 177, 701-713.

James, M. N. G. \& Sielecki, A. R. (1983). J. Mol. Biol. $163,299-361$
Jones, T. A. \& Liljas, L. (1984). J. Mol. Biol. 177, $735-767$.

Kabsch, W. \& Sander, C. (1983). Biopolymers, 22, 25772637.

Knowles, J. R. (1987). Science, 236, 1252-1258

Korn, G. A. \& Korn, T. M. (1968). Mathematical Handbook for Scientists and Engineers, pp. 10-11, McGraw-Hill Book Company, New York.

Ladner, R. C., Heidner, E. G. \& Perutz, M. F. (1977) J. Mol. Biol. 114, 385-414.

Lascombe, M. B., Alzari, P. M., Boulot, G., Saludjian, P. Tougard, P., Berek, C., Haba, S., Rosen, E. M. Nisonoff, A. \& Poljak, R. J. (1989). Proc. Nat. Acad. Sci., U.S.A. 86, 607-611.

Lesk, A. M. \& Chothia, C. (1980). J. Mol. Biol. 136 , $225-270$.

Lesk, A. M. \& Chothia, C. (1982). J. Mol. Biol. 160, $325-342$

Lim, W. A. \& Sauer, R. T. (1989). Nature (London), 339 $31-36$.

Love, R. A. \& Stroud, R. M. (1986). Protein Eng. 1 , $37-46$.

Luo, M., Vriend, G., Kamer, G., Minor, I., Arnold, E. Rossmann, M. G., Boege, U., Scraba, D. G., Duke, G. M. \& Palmenberg, A. C. (1987). Science, 235 , 182-191.

Malcom, B. A., Wilson, K. P., Matthews, B. W., Kirsh, J. F. \& Wilson, A. C. (1990). Nature (London), 345 , $86-89$.

Marquart, M., Deisenhofer, J., Huber, R. \& Palm, W (1980). .J. Mol. Biol. 141, 369-391

Marquart, M., Walter, J., Deisenhofer, J., Bode, W. \& Huber, R. (1983). Acta Crystallogr. sect. B, 39 $480-490$

Matsuura, Y., Takano, T. \& Dickerson, R. E. (1982) J. Mol. Biol. 156, 389-409.

Myer, E., Cole, G., Radhakrishnan, R. \& Epp, O. (1988) Acta Crystallogr. sect. B, 44, 26-38.

Moews, P. C. \& Kretsinger, R. H. (1975). J. Mol. Biol. 91 201-228.

Moult, J., Sussman, F. \& James, M. N. G. (1985). J. Mol. Biol. 182, 555-566.

Navia, M. A., Segal, D. M., Padlan, E. A., Davies, D. R. Rao, N., Rudikoff, S. \& Potter, M. (1979). Proc. Nat. Acad. Sci., U.S.A. 76, 4071-4074.

Ochi, H., Hata, Y., Tanaka, N., Kakudo, M., Sakurai, T., Aihara, S. \& Morita, Y. (1983). J. Mol. Bivl. 166 $407-418$.

Paehler, A., Banerjee, A., Dattagupta, J. K., Fujiwara, T., Lindner, K., Pal, G. P., Suck, D., Weber, G. \& Saenger, W. (1984). EMBO J. 3, 1311-1314.

Palau, J., Argos, P. \& Puigdomenech, P. (1982). Int. J Protein Pept. Res. 91, 394-401.

Pearl, L. \& Blundell, T. (1984). FEBS Letters, 174 , $96-111$

Phillips, S. E. V. (1980). J. Mol. Biol 142, 531-554.

Read, R. J. \& James, M. N. G. (1988). J. Mol. Biol. 200 $523-551$

Read, R. J., Fujinaga, M., Sielecki, A. R. \& James, N. M. G. (1983). Biochemistry, 22, 4420-4433.

Remington, S. J., Woodbury, R. G. \& Reynolds, R. A. (1988). Biochemistry, 27, 8097-8105.

Rossmann, M. G. \& Argos, P. (1976). J. Mol. Biol. 105, $75-95$.

Rossmann, M. G. \& Argos, P. (1977). J. Mol. Biol. 109, 99-129.

Rossmann, M. G. \& Argos, P. (1981). Annu. Rev. Biochem. $50,497-532$

Rossman, M. G., Abad-Zapatero, C., Murthy, M. R. N., 
Liljas, L., Jones, T. A. \& Strandberg, B. (1983). J. Mol. Biol. 165, 711-736.

Salemme, F. R., Freer, S. T., Xuong, N. H., Alden, R. A \& Kraut, J. (1973). J. Biol. Chem. 248, 3910-3921.

Sali, A., Overington, J. P., Johnson, M. S. \& Blundell, T. L. (1990). Trends Biochem. Sci. 15, 235-240.

Satyshur, K. A., Sambhrao, S. T., Pyzalska, D., Drendel, W., Greaser, M. \& Sundaralingan, M. (1988). J. Biol. Chem. 263, 1628-1647.

Saul, F. A., Amzel, L.M. \& Poljak, R. J. (1978). J. Biol. Chem. 253, 585-597.

Scouloudi, H. \& Backer, E. N. (1978). J. Mol. Biol. 126, $637-660$

Segal, D. - Padlan, E. A., Cohen, G. H., Rudikoff, S., Potter, M. \& Davies, D. R. (1974). Proc. Nat. Acad. Sci., U.S.A. 71, 4298-4302.

Shaw, W. V. (1987). Biochem. J. 246, 1-17.

Sheriff, S., Silverton, E. W., Padlan, E. A., Cohen, G. H. Smith-Gill, S. J., Finzel, B. C. \& Davies, D. R. (1987). Proc. Nat. Acad. Sci., U.S.A. 84, 8075-8079.

Silva, A. M. \& Rossmann, M. G. (1985). Acta Crystallogr. sect. $B, 41,147-157$.

Sprang, S., Standing, T., Fletterick, R. J., Stroud, R. M., Finer-Moore, J., Xuong, N. H., Hamlin, R., Rutter, W. J. \& Craik, C. S. (1987). Science, 237, 905909 .
Steigemann, W. \& Weber, E. (1979). J. Mol. Biol. 127, 309-338.

Suguna, K., Bott, R. R., Padlan, E. A., Subramanian, E., Sheriff, S., Cohen, G. H. \& Davies, D. R. (1987). J. Mol. Biol. 196, 877-900.

Szebenyi, D. M. \& Moffat, K. (1986). J. Biol. Chem. 261 , 8761-8777.

Takano, T. \& Dickerson, R. E. (1980). Proc. Nal. Acad. Sci., U.S.A. 77, 6371-6375.

Tanaka, N., Yamane, T., Tsukihara, T., Ashida, T. \& Kakudo, M. (1975). J. Biochem. 77, 147-162.

Timkovich, R. \& Dickerson, R. E. (1976). J. Biol. Chem. 251, 4033-4046.

Tsernoglou, D., Petsko, G. A. \& Hudson, R. A. (1978). Mol. Pharmacol. 14, 710-716.

Tsukada, H. \& Blow, D. M. (1985). J. Mol. Biol. 184, $703-711$

Vainshtein, B. K., Arutyunyan, E. G., Kuranova, I. P., Borisov, V. V., Sosfenov, N. I., Pavlovskii, A. G., Grebenko, A. I., Konareva, N. V. \& Nekrasov, Y. V. (1977). Dokl. Biochem. (English translation), 233, $67-70$.

Walkinshaw, M. D., Saenger, W. \& Maelicke, A. (1980). Proc. Nat. Acad. Sci., U.S.A. 77, 2400-2404.

Zvelebil, M. J. J. M. \& Sternberg, M. J. E. (1988). Protein Eng. 2, 127-138. 